\title{
External referencing and pharmaceutical price negotiation ${ }^{*}$
}

\author{
Begoña Garcia Mariñoso ${ }^{\mathrm{a}}$, Izabela Jelovac ${ }^{\mathrm{b}}$, Pau Olivella ${ }^{\mathrm{c}}$
}

\begin{abstract}
External referencing (ER) imposes a price cap for pharmaceuticals based on prices of identical or comparable products in foreign countries. Suppose a foreign country (F) negotiates prices with a pharmaceutical firm while a home country $(\mathrm{H})$ can either negotiate prices independently or implement ER based on the foreign price. We show that country $\mathrm{H}$ prefers ER if copayments in $\mathrm{H}$ are relatively high. This preference is reinforced when H's population is small. Irrespective of relative country sizes, ER by country H harms country F. Our model is inspired by the wide European experience with this cost containment policy. Namely, in Europe, drug authorization and price negotiations are carried out by separate agencies. We confirm our main results in two extensions. The first one allows for therapeutic competition between drugs. In the second one, drug authorization and price negotiation take place in a single agency.
\end{abstract}

Keywords: Pharmaceuticals, external referencing, price negotiation.

JEL codes: L65, I18.

The authors wish to make it explicit that (i) potential conflicts do not exist either in terms of financial or personal relationships between themselves and others that might bias their work and (ii) that it does not contain any elements that could represent a conflict with ethic issues.

This manuscript contains original unpublished work and is not being submitted for publication elsewhere.

RUNING HEAD: External referencing and price negotiation

\footnotetext{
* The authors thank Kurt Brekke and Miguel Gouveia, who discussed a previous version of this paper at the 5th European Health Economics Workshop and the iHEA world meetings in Barcelona, respectively. We also benefited from suggestions by Pedro Barros, Albert Ma, Michael Manove, Xavier Martinez-Giralt, Tanguy van Ypersele. On the real world cases, we have greatly benefited from discussions with Miquel Carreño, Claudie Charbonneau, Laura Diego, Guillem López Casanovas, Javier García del Pozo, Michael McLellan, Jorge Mestre-Ferrandiz, Mariluz Ojeda, and Yeesha Poon. We gratefully acknowledge the financial support of the Risk Foundation (Health, Risk and Insurance Chair, Allianz). Olivella acknowledges financial support from projects SEJ2006-00538, ECO20097616, Consolider-Ingenio CSD2006-16, 2009SGR-169, and Barcelona Economics-Xarxa CREA. Olivella is a Research Fellow of MOVE (Markets, Organizations and Votes in Economics).

${ }^{\text {a }}$ Comisión del Mercado de las Telecomunicaciones, c. de la Marina, 16-18, 08005 Barcelona, Spain. E-mail: bgmarinoso@cmt.es

${ }^{\mathrm{b}}$ University of Lyon, Lyon, F-69003, France; CNRS, UMR 5824, GATE, Ecully, F-69130, France; ENS LSH, Lyon, F-69007, France. E-mail. jelovac@gate.cnrs.fr

${ }^{\mathrm{c}}$ Corresponding author. Department of Economics and CODE. Universitat Autònoma de Barcelona, Edifici B, 08193 Bellaterra, Barcelona, Spain. E-mail: pau.olivella@uab.es; tel. 34 935812369; fax 34 935813767.
} 


\section{INTRODUCTION}

External referencing (ER) consists in setting a price cap for pharmaceuticals, based on prices of identical or comparable products in other countries. The aim of this paper is to analyze the effects of adopting ER on the pricing mechanisms. This analysis allows us to identify the winners and the losers from such a policy.

With very few exceptions, most countries in the industrialized world have implemented ER at some point of time. Indeed, the policy has been in place in all European countries except Bulgaria, Cyprus, Germany, Malta and the UK. PuigJunoy (2004) states that "the conditions on the EU market are in effect weakening the use of [cost-based price regulation] and giving more importance to the observed price in other European countries (external reference pricing).” (p. 163.) Heuer et al. (2007) reach a similar conclusion from their formal empirical analysis. They explore whether countries engaging in ER suffer from delays in the launch of pharmaceutical products, a good proxy for the importance of ER. Despite the fact that they explore several costcontainment policies as explanatory variables (therapeutic value, cost-effectiveness, and so on), it is suggestive that the dummy variable for the presence of ER is the only explanatory variable that is significant at the 5\% level. Windmeijer et al. (2006) measure the effects of the implementation of ER in the Netherlands. They show that this policy resulted in considerably lower prices in general. Merkur and Mossialos (2007) simulate the effect of ER on drug prices in Cyprus and show that this effect is beneficial after identifying Cyprus as a high price country for pharmaceuticals. Both Anke (2008) and Stargardt \& Schreyogg (2006) analyze the international drug price interdependencies resulting from the adoption of varying forms of ER. They also discuss implications in terms of strategic decisions by firms to sequentially launch drugs in different countries.

These experiences raise the following question: What is the influence of the ER policy on the reference countries and the pharmaceutical firms? To tackle this question, we first need to understand the pricing mechanisms that are driven by ER. We use a model where a pharmaceutical firm (simply "the firm” henceforth) sells a drug in two countries, namely a home country $(\mathrm{H})$ and a foreign country $(\mathrm{F})$. Each country can either negotiate a price directly with the firm or engage in ER. If no country engages in ER, then each country negotiates prices independently of the 
other. We refer to this situation as "independent price negotiations" (IPN henceforth). We assume that the firm is based on a third country, so that both the foreign and the home country will unambiguously benefit from any price decrease. We use the Generalized Nash Bargaining Solution (GNBS) to solve each negotiation problem (on GNBS, see Muthoo, 1999).

We introduce some asymmetries between countries in the population sizes and levels of copayments. Without loss of generality, we assume that country $\mathrm{H}$ has the lowest copayment. We limit ourselves to these two sources of asymmetry between countries to conveniently identify the mechanisms associated with ER. We acknowledge that other sources of asymmetry may coexist and could be determinant to explain the setting of international prices, but their inclusion in our model would not enrich the analysis of the specific effects of ER. However, the influence of both country sizes and copayments should not be overestimated as they are but a subset of relevant determinants of drug pricing. ${ }^{1}$

In our main contribution we assume that countries are unable to threaten the firm with not authorizing the drug for sale in case of a negotiation failure. The only threat available to countries is that of not listing the drug for reimbursement. In other words, even if negotiations fail, the firm can still sell the drug at any price of its choice, but with no subsidy. This assumption is motivated by the fact that, in Europe, pricenegotiating agencies have a minor role in the authorization of drugs. We therefore say that in Europe we are in a "weak threats" scenario. We elaborate this point further in the next section. However, as an extension, we also analyze a situation where agencies can threaten to ban the drug altogether when negotiations fail, which we refer to as the "tough threats" scenario. Indeed, some countries outside Europe like Brazil or Canada are known to threaten firms with not authorizing drug sales if negotiations fail or if the firm does not accept ER.

We analyze how the commitment by a country to engage in ER affects the negotiations in the reference country and ultimately determines the firm's total profit. We do that in three different scenarios. Our central case focus on the weak threats

\footnotetext{
${ }^{1}$ Other sources of asymmetries could be differences in income, in bargaining powers or in specific population needs, for example.
} 
scenario and it ignores the existence of possible therapeutic substitutes. It constitutes a first step to understand the effects driven by ER only. We further extend our main analysis to account for competition between the firm's pharmaceutical product and a therapeutic substitute that is already present on the market in both countries. This extension adds realism to our modeling approach. In particular, it makes the weak threats scenario compatible with the observation that, in most European markets, being excluded from the public funding may be almost as bad as being banned, since sales out of the positive list of reimbursed drugs are negligible if subsidized therapeutic substitutes are available. Another extension maintains the initial monopoly setting but allows for tough threats by the agencies.

The main results of the paper are the following. First, under weak threats and no therapeutic competition, an ER policy by the home country increases the negotiated foreign price, which harms the foreign country. Second, despite this price increase, the home country prefers ER to an independent price negotiation if the consumer copayment in the home country is relatively high. However, this preference diminishes as the demand size grows in the home country relative to the foreign country, although this preference does not disappear. Third, when compared to the profits resulting from IPN, an ER policy brings an increase in the profits derived from the foreign country and a decrease in those derived from the home country. The second effect is strong enough so that overall profits decrease.

All these results are confirmed for the case of therapeutic competition between drugs, except for the size effect that is absent because for simplicity we ignore the asymmetry in country size in this extension.

As for the tough threats scenario, we show that our main insight -that the home country is benefited while ER harms the firm- still holds. However, in contrast to the weak threats scenario, the negotiated price in the foreign country is unaffected by ER, so that ER does not affect the foreign country.

Before offering an intuitive explanation for our results, let us point out that it is not the aim of this paper to provide an explanation of why copayments differ from one country to the other. Certainly, we take copayments as given, carrying out our analysis for any possible configuration of copayments. Therefore, we are implicitly 
assuming that it takes time to change copayments, whereas prices are negotiated in a more agile and case-by-case basis. Since copayments are the prices actually borne by consumers, issues of social equity, insurance, consumer externalities, and even savings in administrative costs are present in the setting of copayments. Moreover, the experience in the EU is that copayments are generally not dependent on each drug and that at most we observe different copayments for large groups of medications (say chronic versus acute treatments) set by law. Notice that, again because copayment is the price borne by the consumer, it is in the copayment negotiation where the usual price discrimination issues would play a decisive role. By taking copayments as given our analysis constitutes a necessary first step in a more ambitious agenda of analyzing the reimbursement system as a whole.

Let us now offer some intuition for our results. External referencing under weak threats makes the firm more aggressive towards the foreign country. We explain this as follows. A negotiation failure would be transmitted to the home country providing the corresponding additional disagreement payoff to the firm. A negotiation success would be transmitted in the same way to the home country providing an additional payoff to the firm again. However, the difference between success and failure payoffs decreases because the demand in country $\mathrm{H}$ is proportionally lower than in country $\mathrm{F}$ when negotiations succeed, due to different copayments. Therefore, the price needs to be higher for the firm not to prefer a negotiation failure. As the size of the home country increases, this effect is reinforced. This explains why ER becomes less and less attractive for the home country as its size becomes more important. The reason why this does not happen under tough threats (i.e., under tough threats negotiations in the foreign country are unaffected by ER) is that the threat point in the home country negotiation is the same regardless of the presence or absence of ER. To see this, suppose that ER is absent. Then if negotiations in the foreign country fail, the drug is banned so the firm makes no profits. Suppose that ER is present. If negotiations in the foreign country fail, the drug is banned in both countries, so again the firm makes no profits. 
Apart from the works by Windmeijer et al. (2006) and Heuer et al. (2007) mentioned above, there are several empirical studies that analyze the impact of price regulation. ${ }^{2}$ Unfortunately, more than exploring the effects of ER in isolation, most empirical studies aim at determining the effect of price controls in general. The empirical implication of our model (the effects of demand size, consumer copayment, and the separation of authorization and subsidization decisions) might serve as a guide for future empirical studies on the effects of ER as a cost control policy.

The paper is organized as follows. A description of the European experience with ER is provided in Section 2. The model is described in Section 3. In Section 4 we provide the solution to the benchmark case in which each country negotiates the price with the pharmaceutical firm independently of the other country. In Section 5 we introduce the possibility that one country adopts a weak-threats ER policy, and we analyze its effects. In Section 6 we extend the analysis to therapeutic competition and in Section 7 to the tough-threats scenario. Section 8 concludes. All the proofs are in the appendix.

\section{THE EUROPEAN EXPERIENCE}

Let us now overview the many instances of ER that one can find in Europe. ${ }^{3}$ These cases motivate our assumption that countries cannot threaten not to authorize drugs for sale if price negotiations fail or if the firm rejects the ER policy.

Many countries in Europe have implemented ER. However, not only the policy details differ from country to country, but are also changed often. For instance, in Denmark, foreign prices were used to determine the reimbursement price for drugs with the same ATC-code, but this policy has been discontinued recently, and has been replaced by non-price controls. In Sweden, ER was discontinued in 2002. Hence, the situation is, to say the least, volatile and the examples given below are only valid as of the time of writing this section.

\footnotetext{
2 On the effects of regulation on price see, for instance, Danzon and Chao (2000a, 2000b). On the effects of regulation on launch delays see Danzon, Wang and Wang (2005) and Kyle (2007).

${ }^{3}$ There are countries outside Europe that also have implemented ER: Brazil (lowest price); Canada (median price); Japan, Korea, and Taiwan (average price).
} 
As for inter-country differences, some administrations use the prices of other countries to construct an average reference price, whereas others take as a reference the minimum price. Among the first ones, some use a large list of referenced foreign countries. For instance Austria uses prices from Denmark, Finland, France, Germany, Greece, Italy, the Netherlands, Portugal, Spain, Sweden, and the UK. Finland adds to the previous list prices from Austria, Belgium, Ireland, and Norway. Also, among countries using average prices, others use prices from just a handful of countries. For instance, in the Netherlands, the maximum price for a drug is established as an average of the prices of the same drug in Germany, France, UK, and Belgium. In Switzerland, the drug price should not exceed the average of the prices in Germany, Denmark, the Netherlands and the UK. Other countries that take averages of other countries’ prices are Austria, Belgium, Italy, Lithuania and Norway.

As mentioned, some countries take the minimum instead of the average price. France uses the lowest price among Austria, Belgium, Denmark, Finland, Germany, Greece, Italy, the Netherlands, Portugal, Spain, Sweden, and the UK. Other countries using the same method are: Bulgaria, Croatia, Czech Republic, Estonia, Greece, Hungary, Latvia, Poland, Portugal, Romania, ex-Serbia-Montenegro, Slovakia, and Slovenia.

In summary, out of all European Countries, only Bulgaria, Cyprus, Germany, Malta and the UK have not had an ER policy, even though Cyprus is now considering its implementation. ${ }^{4}$

Importantly for our model, there are reasons to believe that most European experiences correspond to the weak threats scenario. The reason is simple. In Europe, drug authorization and price negotiation are separate processes carried out by independent agencies, based on different criteria, and with different time horizons. As Heuer et al. (2007) point out, "[W]ith the introduction of the European Medicines Evaluation Agency (EMEA) in 1995, the EU Member States wanted to harmonize access to the pharmaceutical market” so that “[...] companies benefit from a larger market after authorization.” (p. 2). As for Switzerland, a non-EU state, Paris and Docteur (2007) report, "to be launched on the Swiss market, pharmaceutical products have to be approved by the Swissmedic [...]. This authorization is valid for 5 years.”

\footnotetext{
${ }^{4}$ See Cyprus Association of Pharmaceutical Companies (2005).
} 
In contrast, "The Federal Office of Public Health (OFSP) regulates both inclusion in the positive list and pricing of reimbursed pharmaceuticals.” The Swiss case is also interesting because the ER policy makes the threat explicit: according to the Health Insurance Law (1996) a 'positive list' of reimbursed pharmaceuticals was introduced. For a drug to be included in this positive list, its price should not exceed the average of the prices in Germany, Denmark, the Netherlands and the UK. This exactly corresponds to our weak-threats scenario. Equally explicit is the Spanish case. According to the Law 29/2006, the drugs that are subsidized by the National Health System are subject to ER, and in these cases the maximum producer price for drugs will be set taking into account "the average price of EU member states that are not subject to exceptional or transitory regimes of industrial property rights.” (Art. 90.)

\section{THE MODEL}

The players in this game are a pharmaceutical firm and the health authorities of two countries, $\mathrm{H}$ (home country) and $\mathrm{F}$ (foreign country). We refer to these players as the firm and the agencies. The firm sells a drug in both countries. It holds a patent for the drug in both countries and produces at no variable cost. ${ }^{5}$ In sections 4,5 , and 7 we assume that the firm does not face competition from any close substitutes, while in Section 6 we relax this assumption.

Both agencies operate a positive list of reimbursed pharmaceuticals. If the drug is listed for reimbursement in country $i$, patients pay a fixed and exogenous copayment $C_{i}$, as long as price is above copayment. If the price is below the copayment we assume that the out-of-pocket payment $Z_{i}, i=\mathrm{F}, \mathrm{H}$, is the price itself (i.e., there are no taxes). Formally,

$$
Z_{i}=\operatorname{Min}\left\{C_{i}, P_{i}\right\}, i=\mathrm{F}, \mathrm{H}
$$

The difference between the price and the copayment, $P_{i}-C_{i}$, if positive, is reimbursed by the agency to the firm. If the drug is not listed for reimbursement then the patients pay the full price of the drug, $P_{i}$.

\footnotetext{
${ }^{5}$ The assumption that variable costs are negligible can be sustained empirically. Moreover, our analysis can be extended to situations with constant returns to scale. Having a positive marginal cost would only involve more complicated calculations, while in essence the results would be the same.
} 
We assume that aggregate demand in country $\mathrm{F}$ is given by $D\left(Z_{F}\right)$, with $D^{\prime}\left(Z_{F}\right)<0$, $D^{\prime \prime}\left(Z_{F}\right) \leq 0$. Note that by assuming that copayments are fixed, demand is independent of the price as long as the drug is listed for reimbursement and its price is above the copayment. Aggregate demand in country $\mathrm{H}$ is $K D\left(Z_{H}\right)$. In other words, country $\mathrm{H}$ is a $K$-replica of country $\mathrm{F}$, with $K>0$ but not necessarily larger than one. ${ }^{6}$ We say that country $\mathrm{H}$ has size $K$ while country $\mathrm{F}$ has size one.

As mentioned above, in sections 4,5 , and 6 we deal with the monopoly case. We denote by $P^{M}$ the monopoly price, which maximizes $P D(P)$. Notice that $P^{M}$ is the same for both countries (and therefore independent of country size) due to two assumptions: zero variable costs (and in general due to constant returns to scale gross of sunk costs), and country $\mathrm{H}$ being a K-replica of country F.

The following assumption reflects another asymmetry between the two countries.

Assumption 1. If the drug is listed for reimbursement in both countries, patients pay less in country $F$ than in country $H$, and they pay less than the monopoly price, $P^{M}$, in both countries. In other words: $C_{F}<C_{H}<P^{M}$.

Assumption 1 only rules out the case were the two copayments coincide. Note also that if $C_{i}>P^{M}$, this is tantamount to the drug being delisted.

Countries $\mathrm{F}$ and $\mathrm{H}$ have different aggregate demands for two reasons. One is country size. The other is that, as long as country prices are larger than copayments, even if an individual in $\mathrm{F}$ has the same demand function as another in $\mathrm{H}$ and even if factory prices are the same in the two countries, the latter individual will demand less due to the higher copayment.

The pharmaceutical firm aims at maximizing its joint profit from both countries, with $P_{F} D\left(Z_{F}\right)$ being profit in country $\mathrm{F}$ and $P_{H} K D\left(Z_{H}\right)$ being profit in country $\mathrm{H}$.

\footnotetext{
${ }^{6}$ Suppose that, as for the individual demand function for the drug, there are $T$ different types of individuals in country F, $t=1,2, \ldots, T$. We are assuming that if there are $n_{t}$ agents of type $t$ in country $\mathrm{F}$ then there are $K n_{t}$ agents of exactly the same type in country $\mathrm{H}$, for all $t=1,2, \ldots, T$. Assuming that $\mathrm{H}$ is a $\mathrm{K}$-replica of $\mathrm{F}$ simplifies our analysis without giving up realism when considering countries that have similar distributions of socio-economic categories.
} 
We assume that, in each country $i$, copayments are exogenously set beforehand by some outside player (say the Government or the Parliament of this country). Hence, as explained in the introduction, we do not aim at studying what the optimal copayment $C_{i}$ should be. Therefore, the agency only bargains for low prices with firms in return for reimbursement rights. We believe this encompasses most real world cases. ${ }^{7}$

We assume that the agency is given the following mandate by the outside player: She should negotiate prices with the firm in order to maximize net consumer surplus minus the public costs of provision. Hence, the agency's objective function does not include the profits of the firm. We believe this assumption to be in accordance with reality, especially in countries with a few or small pharmaceutical firms. Another motivation might be that the outside player finds it beneficial to delegate the bargaining over price to a more aggressive negotiator.

Now, in a market of size $K_{i}$, with $K_{i}=\{1, K\}$, we define the net consumer surplus as:

$$
K_{i} C S\left(Z_{i}\right)=K_{i}\left[\int_{0}^{D\left(Z_{i}\right)} D^{-1}(q) d q-Z_{i} \cdot D\left(Z_{i}\right)\right] \cdot{ }^{8}
$$

The objective function of the agency of a country of size $K_{i}$ is:

$$
K_{i} C S\left(Z_{i}\right)-K_{i}\left(P_{i}-Z_{i}\right) \cdot D\left(Z_{i}\right) .^{9}
$$

\footnotetext{
${ }^{7}$ Some countries rely on the so-called "tiered pricing" whereby lower prices result in the drug enjoying a higher subsidy. Our model amounts to a very simple tiered pricing mechanism. As it will be explained below, negotiation failure results in the drug not being listed for subsidization. Hence, only two tiers are present: a subsidy $P-C_{i}$ or no subsidy at all.

${ }^{8}$ We consider the consumer surplus as a measure of health benefits as it is linked to the willingness to pay for the drug.

${ }^{9}$ Notice that, if $P_{i}<C_{i}$ then $Z_{i}=P_{i}$ and the objective function becomes $K_{i} \cdot \operatorname{CS}\left(P_{i}\right)$. Notice also that, if $P_{i}$ $>C_{i}$ then $Z_{i}=C_{i}$ and the objective function of the agency is decreasing in $C_{i}$. Although we take copayments as exogenous, it is useful to understand why this is so. Suppose that one increases the copayment so that demand is reduced by one unit. This has a negative effect on gross consumer surplus equal to the original copayment, as the unit that is no longer sold was enjoyed by the marginal consumer. However, it also has a positive effect, as total expenditures (consumer plus government's) are reduced by the price. Since our premise was that copayment was below price, the assumed objective function increases. In consequence, if the agency were in charge of setting copayments, drug consumption would not be subsidized. However, as explained in the introduction, the outside player's preferences may be quite different from those of the agency.
} 
We model the negotiation process as a Nash bargaining game. We initially assume that the scenario is one with weak-threats. Namely, if negotiations fail in a country, the drug is not listed for reimbursement but the firm is allowed to market the product in that country. Of course, the firm will do so at the monopoly price, $P^{M}$. If the drug is not listed for reimbursement, there are no public expenses associated with subsidizing the drug and the objective function of the government reduces to $K_{i} C S\left(P^{M}\right)$, the value of the net consumer surplus at the monopoly price.

Finally, the agencies of both countries have the same bargaining power as the firm, thus equal to $1 / 2$ for each bilateral negotiation. Our results continue to hold for any distribution of bargaining powers among agencies and the firm as long as the relative negotiation powers of the agencies are identical and not too high.

Throughout the text we denote $D^{M}=D\left(P^{M}\right), C S^{M}=C S\left(P^{M}\right)$ and $\pi^{M}=P^{M} D^{M}$. We also denote $D_{i}=D\left(C_{i}\right), D_{i}^{\prime}=D^{\prime}\left(C_{i}\right), C S_{i}=C S\left(C_{i}\right)$ and $C S_{i}^{\prime}=C S^{\prime}\left(C_{i}\right)$ for $i=F$, $H$.

\section{INDEPENDENT PRICE NEGOTIATIONS}

Here we present our main benchmark case in which each country carries a price negotiation with the pharmaceutical firm, independently from the other country, and in the scenario with weak threats. ${ }^{10}$ Therefore, $K_{i} \cdot C S^{M}$ and $K_{i} \pi^{M}$ constitute the disagreement payoffs of the agency and the firm, respectively.

The Nash bargaining problem for a country $i$ of size $K_{i}=\{1, K\}$ is:

\section{Maximize}

$P_{i}$

$$
\begin{aligned}
N B_{1 i} & =\frac{1}{2} \ln \left\{K_{i}\left[C S\left(Z_{i}\right)-\left(P_{i}-Z_{i}\right) D\left(Z_{i}\right)-C S^{M}\right]\right\}+\frac{1}{2} \ln \left\{K_{i}\left[P_{i} D\left(Z_{i}\right)-\pi^{M}\right]\right\} \\
& =\ln \left[K_{i}\right]+\frac{1}{2} \ln \left[C S\left(Z_{i}\right)-\left(P_{i}-Z_{i}\right) D\left(Z_{i}\right)-C S^{M}\right]+\frac{1}{2} \ln \left[P_{i} D\left(Z_{i}\right)-\pi^{M}\right]
\end{aligned}
$$

subject to: $Z_{i}=\operatorname{Min}\left\{C_{i}, P_{i}\right\}$.

\footnotetext{
${ }^{10}$ This analysis heavily draws from Jelovac (2003).
} 
It is worth noting that in the bargaining problem of any country, we assume that the agency places no value on the consumer surplus or the public expenses of the other country. Note also that the size of the country, $K_{i}$, only constitutes a level effect in this bargaining problem, and in consequence will not affect the final price. By solving (1) we obtain the following lemma.

Lemma 1. When both countries independently negotiate the price with the firm, then (i) the resulting price in each country $i, i=F, H$ is:

$$
P_{i}^{*}=\frac{1}{2}\left\{C_{i}+\frac{C S_{i}-C S^{M}}{D_{i}}+\frac{\pi^{M}}{D_{i}}\right\} \text {. }
$$

(ii) This price is increasing in the level of copayment, $C_{i}$, and

(iii) $P_{i}^{*}>C_{i}$ for all $i=F, H$.

The profits per capita in the bargaining solution in country $i$ are:

$$
\pi_{i}^{*}=P_{i}^{*} D_{i}=\frac{1}{2}\left\{C_{i} D_{i}+C S_{i}-C S^{M}+\pi^{M}\right\}
$$

These profits decrease in $C_{i}$, since $C S_{i}^{\prime}=-D_{i}$ implies $\partial \pi_{i}^{*} / \partial C_{i}=C_{i} D_{i}^{\prime} / 2<0$. Since $C_{F}<C_{H}$ by Assumption 1, profits per capita are larger in country F.

Part (i) of Lemma 1 implies the following equality:

$$
C S_{i}-C S^{M}-\left(P_{i}^{*}-C_{i}\right) D_{i}=P_{i}^{*} D_{i}-\pi^{M}
$$

Equation (3) illustrates that the surplus generated by the negotiation above the disagreement point is equally split between the country and the firm, as usual when bargaining powers are equal.

In the bargaining problem, the disagreement point does not depend on the copayment $C_{i}$. Hence, the effect of the copayment on the negotiated price is only due to its effect on the surplus generated by the negotiation above the disagreement point. Let $S\left(C_{i}\right)$ denote this surplus, with:

$$
S\left(C_{i}\right)=C S_{i}+C_{i} D_{i}-C S^{M}-\pi^{M}
$$


This surplus is decreasing in $C_{i}: S^{\prime}\left(C_{i}\right)=C S_{i}^{\prime}+D_{i}+C_{i} D_{i}^{\prime}=C_{i} D_{i}^{\prime}<0$.

As the copayment increases, there is less to be split between the two parties and the negotiated solution converges to the monopoly outcome. The public costs of the subsidy decrease, and the agency can afford higher negotiated prices. At the same time, as the copayment increases, there is less for the firm to gain by negotiating and hence it requires a larger price. This explains Lemma 1 . What follows is a direct corollary of Part (ii) of Lemma 1.

Corollary 2. For any $K_{i}$ and with independent negotiations, the negotiated price in the country with a large copayment exceeds the negotiated price in the country with a small copayment: $P_{F}^{*}<P_{H}^{*}$.

Therefore, when considering the possibility of adopting ER, country $\mathrm{H}$ is a natural country for adopting ER and country F for being the reference country. In the next section we analyze this case and we discuss whether it is indeed the equilibrium of a game where both countries have the choice of whether to implement an ER or not.

\section{EXTERNAL REFERENCING IN THE WEAK-THREATS SCENARIO}

In this section we consider the effects of an ER policy by $\mathrm{H}$ based on the price of country F. Our aim is to explain how H's ER affects the bargaining outcome in country $\mathrm{F}$ and to investigate whether it is in the interest of $\mathrm{H}$ to implement this policy. Let us first specify what happens in the case of failed negotiations in F. As we are under the weak-threat scenario, we assume that if negotiations in country F fail, both $\mathrm{H}$ and $\mathrm{F}$ cease to reimburse the drug but still allow the firm to sell the drug at a full price chosen by the firm. Hence the disagreement payoffs of F's agency and the firm become, respectively, $C S^{M}$ and $(1+K) \pi^{M}$. Similarly, we assume that, if the firm decides not to respect the ER policy and sells the drug in country $\mathrm{H}$ at a price higher than the price cap, $\mathrm{H}$ ceases to reimburse the drug but still allows the firm to sell the drug at any price chosen by the firm.

The following table summarizes the types of ER that we analyze in the paper, anticipating the tough threats case developed in Section 7. It shows, for each type of 
threats and possible contingencies, the price paid by patients and the price received by the firm.

\section{[TABLE I AROUND HERE]}

The next lemma provides the solution to the Nash Bargaining Problem in country F when $\mathrm{H}$ uses the price in country $\mathrm{F}$ as reference.

\section{Lemma 3. If}

$$
D_{H}>D_{F} \frac{2 \pi^{M}}{C_{F} D_{F}+C S_{F}-C S^{M}+\pi^{M}},
$$

which holds if $C_{H}$ is not too high, then the negotiated price in country $F$ is given by

$$
P^{E R}=\frac{1}{2}\left[C_{F}+\frac{C S_{F}-C S^{M}}{D_{F}}+\frac{(1+K) \pi^{M}}{D_{F}+K D_{H}}\right] .
$$

Condition (5) ensures that, when solving the Nash Bargaining Problem in country F, we can restrict attention to prices that lie above that which the firm would accept as reference in country $\mathrm{H}$. Intuitively, if the demand in country $\mathrm{H}$ evaluated at the copayment in $\mathrm{H}$ is high enough, the firm benefits a lot from accepting the ER price cap offered by agency $\mathrm{H}$.

Lemma 3 allows us to write the following equality:

$$
\begin{aligned}
& \frac{D_{F}+K D_{H}}{D_{F}}\left\{C S_{F}-\left(P^{E R}-C_{F}\right) D_{F}-C S^{M}\right\} \\
& \left.=\left\{P^{E R}\left(D_{F}+K D_{H}\right)-(1+K) \pi^{M}\right)\right\} .
\end{aligned}
$$

Equation (7) illustrates that the total surplus generated by the negotiation above the disagreement point is split between country $\mathrm{F}$ and the firm in the ratio 1 to

$$
\frac{D_{F}+K D_{H}}{D_{F}}>1 .
$$

This shows that the implicit negotiation power of the firm is higher when country $\mathrm{H}$ engages in ER as compared to independent negotiations. 
It is also interesting to analyze how changes in country H's size $K$ affect the outcome of the negotiation in $\mathrm{F}$ on the face of ER. A raise in $K$ affects the bargaining between $\mathrm{F}$ and the firm in two ways. First, the pie to be shared between both parties is larger. Hence there is an outwards shift in the frontier of the problem. Second, the firm has a stronger disagreement payoff whilst F's disagreement payoff remains the same. The next proposition tells us the outcome of these two effects.

Proposition 4. Suppose that Assumption 1 and condition (5) hold. Then:

(i) $\quad P^{E R}-P_{F}^{*} \geq 0$ and this difference increases in $K$.

(ii) $P^{E R}-P_{H}^{*}<0$. This difference decreases in $K$ and converges to an asymptote as $K$ tends to infinity. This asymptote decreases in the difference $C_{H}$ $-C_{F}$. Therefore, the difference between $P^{E R}$ and $P_{H}^{*}$ decreases monotonically as $C_{F}$ tends to $C_{H}$.

Proposition 4 is illustrated in Figure 1. It implies that $\mathrm{H}$ prefers to commit to an ER policy rather than to engage in independent price negotiations with the firm. It also implies that this preference diminishes as the size of country $\mathrm{H}$ increases and as copayments converge, but it is always positive if $C_{H}>C_{F}$. However, as a direct result of the adoption of ER in country $\mathrm{H}$, the price negotiated in country F raises. This is explained by the change in the differences between failure and success payoffs of $\mathrm{F}$ and the firm. Moreover, as $K$ increases the negotiated price in country $F$ raises, but never to be so high that $\mathrm{H}$ loses out by choosing the ER policy rather than independently negotiating with the firm. Public expenses as well as the firm's profit in country $\mathrm{H}$ are lower. The opposite holds in country F.

\section{[FIGURE 1 AROUND HERE]}

Notice that consumers in either country are not affected by the ER policy since they pay a fixed copayment. In contrast, total profits of the firm decrease. Formally,

Proposition 5. Under Assumption 1 and if condition (5) holds, the total profits of the firm are lower when country $H$ engages in ER, that is,

$$
P^{E R}\left(D_{F}+K D_{H}\right)<P_{F}^{*} D_{F}+P_{H}^{*} K D_{H} .
$$


Consequently, the sum of public expenses in both countries also decreases, implying that the decrease in H's expenses compensates for the extra expenses in country F. This means that if country $\mathrm{H}$ wanted to fully compensate $\mathrm{F}$ for her "free riding", she could do so and still achieve higher welfare than under independent negotiations.

This concludes the analysis of the case where H engages in ER whereas F does not, to which we refer to as "the natural case" in view of the result in Corollary 2. It is now legitimate to wonder whether such a distribution of roles would constitute an equilibrium in a game where all countries have the choice between negotiating and adopting ER. Does any country benefit by unilaterally deviating from the case we study? Consider first a deviation by country H. Such a deviation would take us to the case where both countries conduct independent negotiations with the firm, as in Section 4. According to part (ii) of Proposition 4, this deviation is not in H's interest. Consider now a deviation by country $\mathrm{F}$ leading de facto to a bilateral adoption of ER. Whether such a deviation is beneficial or not to country $\mathrm{F}$ depends on the rules underlying a bilateral ER. To illustrate this point, let us take two alternative interpretations of a bilateral ER policy.

Assume first that bilateral ER reverts to IPN, then country F is indeed better off deviating to ER because $P^{E R}-P_{F}^{*} \geq 0$ by part (i) of Proposition 4. Hence our “natural case” does not constitute a Nash equilibrium. ${ }^{11}$

Suppose instead that a bilateral adoption of ER entails setting a mechanical price cap equal to the other country's price with no other restriction. Then the firm is free to set very high prices provided they are equal across countries. In that case, country $\mathrm{F}$ is worse off deviating to ER and our supposed natural case does constitute a Nash equilibrium.

To sum up, countries' choice between ER and direct negotiation is highly sensitive to the modalities of the bilateral ER. This sensitivity is interesting in itself and constitutes a promising area for future research. It ties naturally with the issue of strategic launch delays of drugs since it is in principle difficult to apply an ER

\footnotetext{
${ }^{11}$ We can formally show that in that specific case, no Nash equilibrium exists when both countries simultaneously chose between ER and direct negotiation. The proof of this statement is available from the authors upon request.
} 
formula when some of the reference prices have not yet been observed. A dynamic model will be needed to deal with these important issues.

Another interesting issue related to ER is that of parallel trade of drugs. Indeed, both ER and parallel trade result in the convergence of international prices. However, the mechanisms leading to converging prices are different. The convergence in prices due to parallel imports is the best response of pharmaceutical firms to the competition they face from parallel imports. In contrast, ER is imposed by agencies and this forces price convergence.

Another difference between ER and parallel trade arises if one considers the possibility of launch delays, which is beyond the scope of this paper. The timing of drug launches in different countries represents a strategic action for the firm when countries engage in ER. As discussed in Anke (2008) and in Stargardt \& Schreyogg (2006), the firm is better off launching its drug in naturally high-price countries first, to influence prices in other countries to its advantage. Such strategic behavior has less reason to appear with parallel trade only. Indeed, a sequential launching of drugs might at most postpone the start of parallel trade but would not influence prices in the long run.

Another issue is that of the coexistence of both phenomena. In our model, ER leads to uniform pricing across countries because it is based on the price of a single reference country. More generally, when ER is based on the average of several countries prices, ${ }^{12}$ less-than-full convergence might be observed. As noted by Maskus (2001), goods that are parallel imported may not be perceived to be of the same quality between markets even if the producer placed them on the market originally, because of differences in packaging or guarantees. This difference in perception leads in Jelovac and Bordoy (2005) to the persistence of different prices among countries even when parallel imports are permitted. Thus, neither parallel trade nor ER necessarily lead to uniform prices. Therefore, there is scope for an ER policy in the presence of parallel imports and vice versa. However, having both parallel imports and ER simultaneously would result in a limited effect of each because of the presence of the

\footnotetext{
${ }^{12}$ For instance, as mentioned in Section 2, in the Netherlands the ER price cap is an average of the prices in Germany, France, UK, and Belgium.
} 
other. It might be interesting to empirically disentangle the effects of ER from those of parallel trade when both coexist, which is the case in the EU.

\section{EXTENSION TO THERAPEUTIC COMPETITION}

Suppose that there are two drugs, 1 and 2, that have similar therapeutic indications, each produced by a different firm, firm 1 and firm 2. This includes the case where drug 1 and drug 2 are off patent and one is the generic substitute of the other, although the consumer perceives them to be different. ${ }^{13}$ Consistently with this therapeutic equivalence, if both drugs are listed then consumers in any given country face the same copayment, although this copayment may differ among countries. Hence let $C_{i}$ be the copayment for these drugs in country $i \in\{F, H\}$. We maintain the assumptions that $C_{H}>C_{F}$ and that marginal production costs are zero.

To avoid the complex issue of simultaneous negotiations with externalities, ${ }^{14}$ we assume that price negotiations for drug 2 were conducted in the past and were successful, so drug 2 is already listed in both the foreign and the home markets. In other words, for all $i=\mathrm{H}, \mathrm{F}$; the health authority in country $i$ has already committed to pay the competitor the price $p_{2 i}$, whereas consumers pay the copayment $C_{i}{ }^{15}$

All consumers place the same base value $v>0$ to the consumption of either drug. However, the two drugs are horizontally differentiated á la Hotelling. ${ }^{16}$ Hence we represent consumers' preferences over each of the two drugs as if each drug is located at either end of a line of length 1 and consumers are distributed uniformly along the line. The intensity of preference for one drug over another is measured by disutility

\footnotetext{
13 See for instance Mestre-Ferrandiz (1999). We discuss the issue of consumer's perceptions below.

${ }^{14}$ If an agency simultaneously negotiates with firms 1 and 2, the two negotiation processes are interlinked as the two drugs share the same market. Notice that this issue is not present when the firm producing drug 1 negotiates with the two agencies in the absence of ER, since the markets are independent and agency in country $\mathrm{H}$ does not care about country $\mathrm{F}$ and vice versa.

15 There are of course other possible negotiation histories in reference to the pricing of drug 2: success in $\mathrm{H}$ and failure in $\mathrm{F}$, success in $\mathrm{F}$ and failure in $\mathrm{H}$, or failure in both countries. We restrict attention to the case "success in both countries" in the spirit of many analyses of multilateral negotiations. See for instance Marshall and Merlo (2004) or Majer (2009).

16 This Hotelling type of model is common in the literature. See for instance Brekke et al. (2007) or Miraldo (2009).
} 
given by $t d$, where $d$ is the distance between the consumer's ideal drug and the one he/she finally purchases. We assume that the value $v$ is very large, so that we can restrict attention to equilibria where the market is fully covered.

In order to have a well-defined problem we make a number of assumptions, which we group as follows to ease exposition.

Assumption 2. (i) $t>C_{H}>C_{F}$; (ii) $p_{2 i}>C_{i}$; (iii) $t \geq p_{2 i}$ for all $i=H, F$.

These assumptions play the following role. If the market for the two drugs was unregulated and the two drugs would compete in prices, the equilibrium would be that both prices are equal to $t .{ }^{17}$ Hence Part (i) ensures that the copayment is below such price. Part (ii) is in the same spirit, but in reference to the mill price for drug 2. Part (iii) ensures that the price of drug 2 in either country is not above the unregulated price $t$.

\subsection{Independent price negotiations}

Let us first analyze the case of independent negotiations, so that the country subscript $i$ is dropped from the notation. The firm's status quo is to sell the drug unsubsidized, knowing that it will engage in price competition with drug 2, whose consumers pay $C$. Demand for drug 1 becomes

$$
D_{1}\left(p_{1}, C\right)=\left\{\begin{array}{lll}
0 & \text { if } & p_{1}>C+t ; \\
\frac{1}{2}+\frac{C-p_{1}}{2 t} & \text { if } & C-t \leq p_{1} \leq C+t \\
1 & \text { if } & p_{1}<C-t .
\end{array}\right.
$$

Profits are therefore given by $p_{1} D_{1}\left(p_{1}, C\right)$. Assuming an interior solution, profits are maximized at

$$
p_{1}=\frac{C+t}{2} \stackrel{\text { def }}{=} p_{1}^{S Q}
$$

\footnotetext{
${ }^{17}$ See equation 7.7 in Tirole (1988) for the case of extreme differentiation and no production costs $(a=$ $b=c=0$ in his notation).
} 
where SQ stands for status quo. This status quo price is indeed interior and above the copayment of drug 2 by part (i) of Assumption 2. ${ }^{18}$ Demand is

$$
D_{1}=(t+C) /(4 t) \stackrel{d e f}{=} D_{1}^{S Q}
$$

and profits are

$$
\Pi=\frac{(C+t)^{2}}{8 t} \stackrel{\text { def }}{=} \Pi^{S Q} .
$$

It is interesting to note that status quo profits tend to zero if transportation costs and the rival's copayment (consumer price) tend to zero. Hence this model converges to the tough threats scenario of next section if drug 2 is a good substitute of drug 1 ( $t$ small) and the copayment for a listed drug tends to marginal cost. In this case, removing a drug from the list of reimbursed drugs is almost as bad as banning its sale.

We turn now to the health authority's status quo in the negotiation. To further simplify the analysis, we assume that the health authority only cares about the base health benefit of the drug $(v)$ and price. In other words, the agency disregards the disutility borne by individuals when they purchase a drug that is not their ideal one. One possible justification for this assumption is that disutility $t d$ might represent some misleading (i.e., persuasive) advertising that does not reflect true physical differences (Fehr and Stevik, 1998). Hence, perceived preferences for each drug dissipate once the drug is actually consumed, although they do of course affect demand, which is based on pre-consumption perceptions.

The agency's status quo payoff becomes $\left(v-p_{1}\right) D_{1}^{S Q}+\left(v-p_{2}\right)\left(1-D_{1}^{S Q}\right)$, where the first term is the agency's net surplus (consumer's gross surplus $v$ minus total consumer plus agency- outlay) arising from consumers who consume drug 1 and the second one from those consuming drug 2 . After substituting prices and demands, this status quo point can be rewritten as

\footnotetext{
${ }^{18}$ To see this; notice that $C<t$ implies that the average $p_{1}=(C+t) / 2$ must lie between $C$ and $t$, and hence also between $C-t$ and $C+t$.
} 


$$
v-\frac{(t+C)^{2}}{8 t}-\frac{3 t-C}{4 t} p_{2} \stackrel{d e f}{=} H^{S Q}
$$

If instead negotiations are successful at price $p_{1}$ then demand for the two drugs is the same and equal to $1 / 2$ since consumers pay the same copayment $C$. Therefore the firm obtains

$$
(1 / 2) p_{1} \stackrel{\text { def }}{=} \Pi\left(p_{1}\right)
$$

The next lemma allows us to restrict attention to prices above the copayment.

Lemma 6. The firm would reject any $p_{1}<C$.

With successful negotiations, the health authority obtains

$$
\frac{v-p_{1}}{2}+\frac{v-p_{2}}{2}=v-\frac{p_{1}+p_{2}}{2} \stackrel{\text { def }}{=} H\left(p_{1}\right)
$$

We can now present the Nash Bargaining Problem (NBP):

$$
\underset{p_{1}}{\operatorname{Max}} \frac{1}{2} \ln \left(H\left(p_{1}\right)-H^{S Q}\right)+\frac{1}{2} \ln \left(\Pi\left(p_{1}\right)-\Pi^{S Q}\right) .
$$

The solution is

$$
p_{1}^{I P N}=\frac{(t+C)^{2}+(t-C) p_{2}}{4 t} .
$$

It is easy to check that Assumption 2 implies $p_{1}^{I P N}>\mathrm{C}$ and that $\frac{\partial p_{1}^{I P N}}{\partial C}>0$, as in Lemma 1.

In order to have a setting that is similar to the one in Section 4, that is, one where independent price negotiations lead to a higher price in the home country, we impose the following. 
Assumption 3. $p_{2 F}<\frac{\left(t+C_{H}\right)^{2}-\left(t+C_{F}\right)^{2}+\left(t-C_{H}\right) p_{2 H}}{t-C_{F}}=p_{2 F}^{M A X}$.

It is interesting to note that Assumption 3 ensures that $p_{1 F}^{I P N}<p_{1 H}^{I P N}$ even when copayments are not higher in country $\mathrm{H}$.

\subsection{External referencing}

Suppose that agency $\mathrm{H}$ engages in ER when pricing drug 1, using the price in $\mathrm{F}$ as a reference price. We now have to deal with the two countries simultaneously, so we need to restore the subindices indicating country. Recall that copayments for this therapeutic group in each country $\left(C_{F}, C_{H}\right)$ as well as mill prices of drug 2 in each country $\left(p_{2 H}, p_{2 F}\right)$ were set in the past. Hence we only need to find the negotiated price for drug 1 in $\mathrm{F}$, or $p_{1}$. Notice first that agency H's success payoff as a function of $p_{1}$ is the same function as in the previous subsection since agencies do not care about other countries’ payoffs. Hence, after duly replacing $C$ by $C_{F}, \Pi^{S Q}$ by $\Pi_{F}^{S Q}$, and $p_{2}$ by $p_{2 F}$ in (10) and (12), leading to $H_{F}^{S Q}$ and $H_{F}\left(p_{1}\right)$, agency F's stakes in the negotiation become $H_{F}\left(p_{1}\right)-H_{F}^{S Q}$. As for the firm, its status quo is to sell the drug unsubsidized in both countries, thus engaging in price competition with drug 2 in both countries. Hence, once we restore the country subindex $i \in\{F, H\}$, the profits become (see (9)):

$$
\Pi_{F}^{S Q}+\Pi_{H}^{S Q}=\frac{\left(t+C_{F}\right)^{2}}{8 t}+\frac{\left(t+C_{H}\right)^{2}}{8 t}
$$

In case of success at price $p_{1}$ in country $\mathrm{F}$, the firm obtains this mill price in both countries. Consumers in $\mathrm{F}$ pay the same copayment $C_{F}$ for the two drugs, and consumers in $\mathrm{H}$ pay the same copayment $C_{H}$ for the two drugs. Hence demands are shared equally in both countries and the firm's profit is given simply by

$$
p_{1}\left(\frac{1}{2}+\frac{1}{2}\right)=p_{1}
$$

In the next lemma we provide the solution to the NBP. 
Lemma 7. Assume that

$$
p_{2 F}>\frac{\left(t+C_{H}\right)^{2}-\left(t+C_{F}\right)^{2}}{t-C_{F}} \stackrel{\text { def }}{=} p_{2 F}^{M I N} .
$$

Then the solution of the NBP in country $F$ is given by

$$
p_{1}^{E R}=\frac{3}{2} \Pi_{F}^{S Q}+\frac{1}{2} \Pi_{H}^{S Q}+\frac{t-C_{F}}{4 t} p_{2 F} .
$$

It is easy to check that the condition (14) is compatible with Assumption 3 and that (14) becomes less stringent the larger $t$ is and/or the closer is $C_{H}$ to $C_{F}$. As in Lemma 3 , this condition ensures that we can restrict attention to prices that lie above that which the firm would accept as reference in country $\mathrm{H}$. The intuition is the following. Suppose $p_{2 F}$ is small. Then the agency in $\mathrm{F}$ has a strong bargaining position vis à vis firm 1: the agency can always resort to drug 2 as a cheap alternative. Once the agency in $\mathrm{F}$ has a strong bargaining position, the negotiated price in $\mathrm{F}$ will be so low that the firm will reject it as price cap in $\mathrm{H}$.

We now confirm that our main results continue to hold in this extension: ER benefits the referencing (high copayment) country and harms the referenced country as well as the firm. Formally show,

Proposition 8. Suppose that $p_{2 F} \in\left(p_{2 F}^{M I N}, p_{2 F}^{M A X}\right)$ so that both Assumption 3 and condition (14) hold. Then,

$$
p_{1 F}^{I P N}<p_{1}^{E R}<p_{1 H}^{I P N} \text { and } \Pi\left(p_{1 F}^{I P N}\right)+\Pi\left(p_{1 H}^{I P N}\right)>2 \Pi\left(p_{1}^{E R}\right),
$$

with $\Pi(\cdot)$ defined in Equation (11).

\section{EXTENSION TO TOUGH THREATS}

As explained in the introduction, our main motivation is to provide insights into the European markets, where price negotiations have no bearing on the drug authorization decision (i.e. only weak threats are feasible). However, it is interesting to see that some of our main results remain even when agencies in charge of price negotiation can also threaten with a ban on the drug. In this section we assume that agencies in countries $\mathrm{F}$ and $\mathrm{H}$ are able to make such tough threats and we restrict our attention to the monopoly case. 
In this case and with independent negotiations, a country's agency does not authorize the drug for sale if the negotiation in this country fails. Similarly, country $\mathrm{H}$ does not authorize the drug for sale if it implements an ER policy and negotiations in country $\mathrm{F}$ fail. Notice that tough threats change the disagreement payoff of both the Nash bargaining problem under independent negotiations and the Nash bargaining problem in $\mathrm{F}$ when $\mathrm{H}$ engages in ER.

Unfortunately, solving the model with tough threats at the same level of generality as the model with weak threats is quite complex. To illustrate this note that with tough threats and independent negotiations the disagreement point is no longer $\left(C S^{M}, \pi^{M}\right)$, but $(0,0)$. This means that it is difficult to rule out situations where price is so low that it falls below the copayment. Hence the analysis needs to deal with the non-differentiability of the patients' payment function. In contrast, under weak threats we avoid this non-differentiability because profits must lie above $\pi^{M}$.

In order to derive some explicit results, we restrict attention to the case of a monopolistic firm facing a linear demand. More precisely, for $\alpha, \psi>0$, let demand be given by

$$
D(Z)=(\alpha-Z) / \psi
$$

We also assume that $C_{F}=0$. This obviously guarantees that the price resulting from any negotiation taking place in country $\mathrm{F}$ is above the copayment in that country. This drastically reduces the number of cases and comparisons that one must address. Of course, we still assume that $0=C_{F}<C_{H}<P^{M}=\alpha / 2$, in order to have an interesting problem.

These assumptions allow us to derive a sufficient condition ensuring that:

i) The price resulting from the Nash bargaining problem with ER by $\mathrm{H}$ is above $C_{H}$.

ii) The price resulting from the Nash bargaining problem when $\mathrm{H}$ conducts independent price negotiations with the firm is also above $C_{H}$.

iii) Agency $\mathrm{H}$ is able to decrease prices using ER. Thus, one of the main results that we obtained under weak threats is maintained. 
iv) In contrast to the weak threats scenario, under tough threats country $F$ is unaffected by ER. In other words, the negotiated price in F is the same irrespective of whether $\mathrm{H}$ engages in ER or not.

v) As a direct result of (iii) and (iv), overall firm’s profits decrease with ER.

Let us formalize these results.

Proposition 9. If $\alpha>4 C_{H}$ then $P_{F}^{I P N}=P^{E R}=\frac{\alpha}{4}>C_{H}$. Moreover, $P_{H}^{I P N}=\frac{\alpha}{4}+\frac{C_{H}}{4}>P^{E R}$ and total firm's profits are lower under $E R$.

Notice that conclusions (i) through (v) are contained in the proposition. Condition $a>4 C_{H}$ ensures that the willingness to pay for the drug in question is high enough so that agencies are willing to pay a relatively high price. This in turn ensures that when we solve the different negotiations (in $\mathrm{H}$ and in $\mathrm{F}$ under IPN, and in $\mathrm{H}$ alone when $\mathrm{F}$ adopts ER) we can restrict attention to prices that lie above the relevant copayment. This allows us to avoid the non-differentiabilities present in the objective function of the Nash Bargaining Problem.

Another feature of ER under tough threats is that the negotiated price becomes independent of $K$. Intuitively, when the threat point is a sales ban in both countries, the size of the home country ceases -trivially- to influence the threat point.

\section{CONCLUSIONS}

Using a model where two countries differ only in their population size and subsidization policies, our most general result is that a country has an incentive to engage in ER if its copayment levels are high as compared to the other country's. This preference dwindles as the relative size of the country engaging in ER increases. We have analyzed the effects of an ER policy by $\mathrm{H}$ on the negotiation in $\mathrm{F}$, showing that ER increases the surplus to be shared between F and the firm. The idea is that the profits obtained by the firm in the home country, $\mathrm{H}$, become part of the pie. 
For the case of ER with weak threats, we can provide a clear empirical prediction that hinges on the relative size of the home country. Perhaps surprisingly, it turns out that the relative size of the home country is irrelevant as to the sign of the advantage of ER over independent negotiations, which is always positive. Only the size of the advantage is affected. In other words, should ER have some external and fixed cost that we have not taken into account, ${ }^{19}$ then ER would only be implemented if the size of the home country were not too large. In a nutshell, only small countries should be observed to engage in ER and/or ER should be based on prices in large countries (or a large group of countries). Our analysis yields an analogous prediction if one substitutes "large country" by "small copayment country" and vice versa.

Our main results continue to hold when therapeutic competition is introduced in our model: ER benefits the country with high copayment while it harms the reference country as well as the pharmaceutical firm.

With tough threats the firm suffers a harsher punishment in the case that negotiations fail. We show that if all countries are able to make tough threats the main result with weak threats turns out to be robust: ER benefits the home country and harms the firm. However, in contrast to the scenario with weak threats, the benefits derived from an ER policy cease to depend on relative country size. Moreover, the negative externality that ER inflicts on the foreign country disappears.

We recognize that there may be other factors that condition price negotiations for a given reimbursement policy, like the prevalence of a given disease or risk mix (say population age), the lobbying activity of the pharmaceutical industry, and so on. Nevertheless, we believe that our analysis offers insights on the direction of the effects of an ER policy. The fact that the reference country could be harmed constitutes one of the main results of our analysis. This policy externality suggests the pharmaceutical pricing policies should be internationally coordinated.

\footnotetext{
${ }^{19}$ For instance, some political cost.
} 


\section{REFERENCES}

Anke R. 2008. Assessing the impact of global price interdependencies. PharmacoEconomics 26: 649-659.

Brekke K, Konigbauer R, Straume IOR. 2007. Reference pricing of pharmaceuticals. Journal of Health Economics 26: 613-42.

Cyprus Association of Pharmaceutical Companies. $\mathrm{MOH}$ circular-new pricing policy. Nicosia. http://www.capc.org.cy/Circular to Importers english.doc [CAPC 2005].

Danzon PM, Chao LW. 2000a. Does regulation drive out competition in pharmaceutical markets. Journal of Law and Economics 43: 311-357.

Danzon PM, Chao LW. 2000b. Cross-national price differences for pharmaceuticals: how large, and why? Journal of Health Economics 19: 159-195.

Danzon PM, Wang YR, Wang L. 2005. The impact of price regulation on the launch delay of new drugs-evidence from twenty-five major markets in the 1990s. Health Economics 14: 269-92.

Fehr NHMVD, Stevik K. 1998. Persuasive advertising and product differentiation. Southern Economic Journal 65: 113-26.

Heuer A, Mejer M, Neuhaus J. 2007. The national regulation of pharmaceutical markets and the timing of new drug launches in Europe. Kiel Institute for the World Economy Working Paper 437.

Jelovac I. 2003. On the relationship between the negotiated price of pharmaceuticals and the patients' copayment. Université de Liège - CREPP working paper 2002/04.

Jelovac I, Bordoy C. 2005. Pricing and welfare implications of parallel imports in the pharmaceutical industry, International Journal of Health Care Finance and Economics 5: 5-21.

Kyle M. 2007. Price controls and entry strategy. Review of Economics and Statistics 89: 88-99.

Majer T. 2009. Does the waterbed effect harm consumers?, Mimeo Universitat Autònoma de Barcelona.

Marshall RC., Merlo A. 2004. Pattern bargaining. International Economic Review 45: 239-55. 
Maskus KE. 2001. Parallel imports in pharmaceuticals: Implications for competition and prices in developing countries. Final Report to the World Intellectual Property Organization.

Merkur S, Mossialos E. 2007. A pricing policy towards the sourcing of cheaper drugs in Cyprus. Health Policy 81: 368-375.

Mestre-Ferrandiz J. 1999. The impact of generic goods in the Pharmaceutical industry. Health Economics 8: 599-612.

Miraldo M. 2009. Reference pricing and firms' pricing strategies. Journal of Health Economics 28: 176-197.

Muthoo A. 1999. Bargaining Theory with Applications. Cambridge University Press: Cambridge; New York and Melbourne.

Paris V, Docteur E. 2007. Pharmaceutical prices and reimbursement policies in Germany. OECD Health Working Papers No. 39.

Puig-Junoy J. 2004. Incentives and pharmaceutical reimbursement reforms in Spain. Health Policy 67: 149-165.

Stargardt T, Schreyogg J. 2006. Impact of cross-reference pricing on pharmaceutical prices: Manufacturers' pricing strategies and price regulation. Applied Health Economics \& Health Policy 5: 235-247.

Tirole J. 1988. The Theory of Industrial Organization. MIT Press: Cambridge, Mass. and London.

Windmeijer F, de Laat E, Douven R, Mot E. 2006. Pharmaceutical promotion and GP prescription behaviour. Health Economics 15: 5-18. 


\section{APPENDIX}

\section{Proof of Lemma 1}

Part (i)

We first prove that $P<C_{i}$ is not feasible in the Nash Bargaining Problem in any country $i=\mathrm{F}, \mathrm{H}$ :

Notice that $P D(P)<\Pi^{M} \equiv P^{M} D\left(P^{M}\right)$, since $P<C_{i}<P^{M}$ and $P^{M}$ maximizes $P D(P)$. Hence, $P D(P)$ is below the disagreement payoff for the firm for any $P<C_{i}$. Therefore, we can restrict attention to $P \geq C_{i}$ so that $Z_{i}=\operatorname{Min}\left\{C_{i}, P\right\}=C_{i}$ can be substituted into (1), which yields

$$
\begin{aligned}
& \stackrel{\text { Maximize }}{p_{i}} \\
& N B_{1 i}=\ln \left[K_{i}\right]+\frac{1}{2} \ln \left[C S\left(C_{i}\right)-\left(P_{i}-C_{i}\right) D_{i}-C S^{M}\right]+\frac{1}{2} \ln \left[P_{i} D_{i}-\pi^{M}\right]
\end{aligned}
$$

The first order condition associated to (A1) can be written as:

$$
\left.\frac{\partial N B_{1 i}}{\partial P_{i}}\right|_{P_{i}^{*}}=-\frac{1}{2} \frac{D_{i}}{C S_{i}-\left(P_{i}^{*}-C_{i}\right) D_{i}-C S^{M}}+\frac{1}{2} \frac{D_{i}}{P_{i}^{*} D_{i}-\pi^{M}}=0 .
$$

Rearranging this expression, equation (2) in Lemma 1 is obtained. This is the solution to (A1) since (A1) is concave in $P$ :

$$
\frac{\partial^{2} N B_{1 i}}{\partial P_{i}^{2}}=-\frac{1}{2}\left[\frac{D_{i}}{C S_{i}-\left(P_{i}-C_{i}\right) D_{i}-C S^{M}}\right]^{2}-\frac{1}{2}\left[\frac{D_{i}}{P_{i} D_{i}-\pi^{M}}\right]^{2}<0 .
$$

Part (ii)

To check that $P_{i}{ }^{*}$ is increasing in $C_{i}$, rewrite the first-order condition associated to (A1) as:

$$
\left(C S_{i}-\left(P_{i}^{*}-C_{i}\right) D_{i}-C S^{M}\right)-\left(P_{i}^{*} D_{i}-\pi^{M}\right)=0 .
$$


Applying the implicit function theorem to this expression and using $C S_{i}^{\prime}=-D_{i}$, we obtain:

$$
\frac{\partial P_{i}^{*}}{\partial C_{i}}=-\frac{\left[C S_{i}^{\prime}+D_{i}-\left(P_{i}^{*}-C_{i}\right) D_{i}^{\prime}\right]-P_{i}^{*} D_{i}^{\prime}}{-D_{i}-D_{i}}=-\frac{D_{i}^{\prime}}{D_{i}}\left[P_{i}^{*}-\frac{C_{i}}{2}\right]
$$

This is positive, since equation (2) implies $P_{i}^{*}>\frac{C_{i}}{2}$.

Part (iii)

We now prove that $P_{i}^{*}>C_{i}, \forall i=F, H$. By definition, $\pi^{M}>P \cdot D(P), \forall P \neq P^{M}$. Therefore, $\quad C_{i}<P^{M} \Rightarrow \frac{\pi^{M}}{D_{i}}>C_{i}$. Moreover, $\quad C_{i}<P^{M} \Rightarrow C S_{i}>C S^{M}$. Therefore, $P_{i}^{*}>C_{i}, \forall i=F, H$.

\section{Proof of Corollary 2}

By part (ii) of Lemma 1 and $C_{F}<C_{H}$.

\section{Proof of Lemma 3}

Assume that $P$ has been set in country $\mathrm{F}$ after successful negotiations. Then ER in $\mathrm{H}$ implies that the price cap imposed by the agency in $\mathrm{H}$ to the firm is $P$. The question is then whether the firm will accept this price cap in Country H. In a complement to this proof that is available upon request from the authors, we show that (i) the answer is yes if $P$ is above threshold $P^{M I N}=\Pi^{M} / D_{H}$, and (ii) that $C_{H}<P^{M I N}<P_{H}{ }^{*}$. This implies that three separate intervals for $P$ must be considered when $\mathrm{F}$ negotiates with the firm, since the formulae for negotiation payoffs are different in each interval. Namely, (i) $P<C_{F}<P^{M I N}$, where $P$ is rejected by the firm in country $\mathrm{H}$ so consumers in $\mathrm{H}$ pay $P^{M}$ while consumers in $\mathrm{F}$ pay $P$; (ii) $C_{F} \leq P<P^{M I N}$, where $P$ is still rejected by the firm so consumers in $\mathrm{H}$ pay $P^{M}$ while consumers in $\mathrm{F}$ pay $C_{F}$; (iii) $C_{H}$ $\leq P^{M I N} \leq P$, where $P$ is accepted by the firm in country $\mathrm{H}$ and consumers in F pay $C_{F}$ while consumers in $\mathrm{H}$ pay $C_{H}$. In the same complement available upon request 
mentioned above, we show that, under condition (5), the Nash bargaining solution in F lies in interval (iii), that is, $P \geq P^{M I N}$. We can now solve the NBP restricting $P$ to be in interval (iii). The problem becomes

$$
\begin{aligned}
& \text { Maximize }\left\{P \geq P^{M I N}\right\} \\
& \frac{1}{2} \ln \left\{C S_{F}-\left(P-C_{F}\right) D_{F}-C S^{M}\right\}+\frac{1}{2} \ln \left\{P\left(D_{F}+K D_{F}\right)-(1+K) \pi^{M}\right\} .
\end{aligned}
$$

The first-order condition can be written as:

$$
-\frac{1}{2} \frac{D_{F}}{C S_{F}-\left(P^{E R}-C_{F}\right) D_{F}-C S^{M}}+\frac{1}{2} \frac{D_{F}+K D_{H}}{P^{E R}\left(D_{F}+K D_{H}\right)-(1+K) \pi^{M}}=0 .
$$

Rearranging this expression, we obtain the formula for $P^{E R}$ given in equation (6).

To show that this is indeed the solution we must prove that it lies above $P^{M I N}$ and that the objective function is concave in $P$. We prove these two statements in the complement available upon request.

\section{Proof of Proposition 4.}

Step 1. Differentiating $P^{E R}$ with respect to $C_{F}$ we obtain:

$$
\frac{\partial P^{E R}}{\partial C_{F}}=\frac{1}{2}\left[1+\frac{C S_{F}^{\prime} D_{F}-D_{F}^{\prime}\left(C S_{F}-C S^{M}\right)}{\left(D_{F}\right)^{2}}\right]-\frac{1}{2} D_{F}^{\prime} \frac{(1+K) \pi^{M}}{\left(D_{F}+K D_{H}\right)^{2}} .
$$

Using the fact that $C S_{F}^{\prime}=-D_{F}$ we can simplify the expression to:

$$
\frac{\partial P^{E R}}{\partial C_{F}}=-\frac{D_{F}^{\prime}}{2}\left[\frac{C S_{F}-C S^{M}}{\left(D_{F}\right)^{2}}+\frac{(1+K) \pi^{M}}{\left(D_{F}+K D_{H}\right)^{2}}\right]>0 .
$$

Step 2. $\frac{\partial P^{E R}}{\partial C_{H}}=-K \frac{D_{H}^{\prime}}{2} \frac{(1+K) \pi^{M}}{\left(D_{F}+K D_{H}\right)^{2}}>0$. 
Step 3. $\frac{\partial P^{E R}}{\partial K}=\frac{\pi^{M}\left(D_{F}-D_{H}\right)}{2\left(D_{F}+K D_{H}\right)^{2}}>0$.

Proof of Part (i)

Using Lemma 1 (for $i=\mathrm{F}$ ) and the fact that $D_{F}>D_{H}$, we can write

$$
P^{E R}=P_{F}^{*}+\frac{1}{2} K \pi^{M}\left[\frac{D_{F}-D_{H}}{D_{F}\left(D_{F}+K D_{H}\right)}\right]>P_{F}^{*} .
$$

Proof of Part (ii)

As $K$ tends to infinity, $P^{E R}$ tends to:

$$
P_{\lim }^{E R}=\frac{1}{2}\left\{C_{F}+\frac{C S_{F}-C S^{M}}{D_{F}}+\frac{\pi^{M}}{D_{H}}\right\}
$$

To compare $P_{\lim }^{E R}$ with $P_{H}^{*}$ as defined in (2), we first define the following auxiliary function:

$$
f(Z)=Z+\frac{C S(Z)-C S^{M}}{D(Z)}
$$

We can now write $P_{\lim }^{E R}=\frac{1}{2}\left\{f\left(C_{F}\right)+\frac{\pi^{M}}{D_{H}}\right\}$ and $P_{H}^{*}=\frac{1}{2}\left\{f\left(C_{H}\right)+\frac{\pi^{M}}{D_{H}}\right\}$. Now, using $C S^{\prime}(Z)=-D(Z)$ and since $Z<P^{M}$, we have that:

$$
f^{\prime}(Z)=-\frac{D^{\prime}(Z)\left[C S(Z)-C S^{M}\right]}{[D(Z)]^{2}}>0
$$

This implies $f\left(C_{F}\right)<f\left(C_{H}\right)$ since $C_{F}<C_{H}$. This implies that $P_{\lim }^{E R}<P_{H}^{*}$. Given that $P^{E R}$ is increasing in $K, P^{E R}-P_{H}^{*}<0, \forall K$. 
The fact that $f^{\prime}(Z)>0$ also implies that the difference $R=P_{H}^{*}-P_{\lim }^{E R}$ decreases as $C_{F}$ tends to $C_{H}$. Therefore, the difference between $P^{E R}$ and $P_{H}^{*}$ decreases monotonically as $C_{F}$ tends to $C_{H}$.

\section{Proof of Proposition 5}

Define $\Delta\left(C_{F}, C_{H}, K\right)=P_{F}^{*} D_{F}+P_{H}^{*} K D_{H}-P^{E R}\left(D_{F}+K D_{H}\right)$. We need to prove that $\Delta\left(C_{F}, C_{H}, K\right)>0$. Suppose first that $K=0$. In this case $P_{F}^{*}=P^{E R}$ and therefore $\Delta\left(C_{F}, C_{H}, 0\right)=\left(P_{F}^{*}-P^{E R}\right) D_{F}=0$. Hence it suffices to prove that $\frac{\partial \Delta}{\partial K}>0$. That is, we need:

$$
\begin{aligned}
\frac{\partial \Delta}{\partial K}= & P_{H}^{*} D_{H}-\left(D_{F}+K D_{H}\right) \frac{\partial P^{E R}}{\partial K}-P^{E R} D_{H} \\
& =\left(P_{H}^{*}-P^{E R}\right) D_{H}-\left(D_{F}+K D_{H}\right) \frac{\partial P^{E R}}{\partial K}>0 .
\end{aligned}
$$

Substituting $P^{E R}$ from Lemma 3, $P_{H}^{*}$ from Lemma 1, and the formula of $\frac{\partial P^{E R}}{\partial K}$ derived in step 3 of the the proof of Proposition 4 we obtain:

$$
\frac{\partial \Delta}{\partial K}=\left[f\left(C_{H}\right)-f\left(C_{F}\right)\right] \frac{D_{H}}{2}+\frac{\pi^{M}}{2}\left[1-\frac{(1+K) D_{H}}{D_{F}+K D_{H}}-\frac{\left(D_{F}-D_{H}\right)}{D_{F}+K D_{H}}\right]
$$

where $f(Z)$ is as defined in the proof of Proposition 4. It is easy to check that the expression in brackets in the second term of the last expression is zero. The expression in brackets in the first term is positive since $f^{\prime}(Z)>0$ as shown in the proof of Proposition 4.

\section{Proof of Lemma 6}

If $p_{1}<C$ then $\Pi\left(p_{1}\right)<(1 / 2) C$ so $\Pi\left(p_{1}\right)-\Pi^{S Q}<\frac{1}{2} C-\frac{(C+t)^{2}}{8 t}=-\frac{(C-t)^{2}}{8 t}<0$. 


\section{Proof of Lemma 7}

Step 1. Show that the firm accepts the H's ER price if it is above $\frac{\left(t+C_{H}\right)^{2}}{4 t} \stackrel{\text { def }}{=}$ $p_{1}^{M I N}$.

To accept the price $p_{1}$ offered under ER, the firm must make more profits by being listed at this price (so consumers pay $C_{H}$ ) than competing at an unsubsidized price with the rival, whose consumers pay $C_{H}$. This can be written as $\frac{p_{1}}{2}>\frac{\left(C_{H}+t\right)^{2}}{8 t}$.

Step 2. Assume that condition (14) holds. Show that the solution of the NBP in country $\mathrm{F}$ is above $p_{1}^{M I N}$.

It is easy to show that, when the firm rejects the ER offer by $\mathrm{H}$, the NBP in F has the same objective function as under IPN in F. Hence if the solution under IPN in F, or $p_{1 F}^{I P N}$, lies above $p_{1}^{M I N}$ then the solution to the whole NBP under ER is indeed above $p_{1}^{M I N}$. Hence, using (13) for $C=C_{F}$ and $p_{2}=p_{2 F}$, we require $\frac{\left(t+C_{H}\right)^{2}}{4 t}<\frac{\left(t+C_{F}\right)^{2}+\left(t-C_{F}\right) p_{2 F}}{4 t}$. This is equivalent to condition (14).

Step 3. We can now present the Nash Bargaining Problem:

$$
\underset{p_{1} \geq p_{1}^{M I N}}{\operatorname{Max}} \frac{1}{2} \ln \left(H_{F}\left(p_{1}\right)-H_{F}^{S Q}\right)+\frac{1}{2} \ln \left(p_{1}-\Pi_{F}^{S Q}-\Pi_{H}^{S Q}\right) .
$$

Step 4. Use the first order conditions of this problem to obtain (15).

\section{Proof of Proposition 8}

Let $p_{1 F}^{I P N}$ be given by the formula for $p_{1}^{I P N}$ once applied to country $\mathrm{F}$, that is, the one given by (13) after substituting $C$ by $C_{F}$ and $\Pi^{S Q}$ by $\Pi_{F}^{S Q}$. Then $p_{1}^{E R}$ can be rewritten as 


$$
p_{1}^{E R}=\frac{1}{2}\left(\Pi_{H}^{S Q}-\Pi_{F}^{S Q}\right)+p_{1 F}^{I P N} .
$$

Since $\Pi^{S Q}$ is an increasing function of $C$, we have $\Pi_{F}^{S Q}<\Pi_{H}^{S Q}$ when $C_{H}>C_{F}$. Therefore $p_{1}^{E R}>p_{1 F}^{I P N}$.

Moreover, to show that $p_{1 H}^{I P N}>p_{1}^{E R}$ we write the difference $p_{1 H}^{I P N}-p_{1}^{E R}$ as follows:

$$
p_{1 H}^{I P N}-p_{1}^{E R}=p_{1 H}^{I P N}-p_{1 F}^{I P N}-\frac{1}{2}\left(\Pi_{H}^{S Q}-\Pi_{F}^{S Q}\right) .
$$

To show that this difference is always positive, first show that it is positive when evaluated at $C_{H}=C_{F}$; then show that this difference is increasing in $C_{H}$.

When $C_{H}=C_{F}, \Pi_{H}^{S Q}=\Pi_{F}^{S Q}$ and $p_{1 H}^{I P N}-p_{1}^{E R}=p_{1 H}^{I P N}-p_{1 F}^{I P N}$, which is positive by Assumption 3.

$$
\frac{\partial\left(p_{1 H}^{I P N}-p_{1}^{E R}\right)}{\partial C_{H}}=\frac{\partial p_{1 H}^{I P N}}{\partial C_{H}}-\frac{1}{2} \frac{\partial \Pi_{H}^{S Q}}{\partial C_{H}}=\frac{3\left(t+C_{H}\right)-2 p_{2 H}}{8 t},
$$

which is positive by part (iii) of Assumption 2.

We use a similar technical argument to show that $\Pi\left(p_{1 F}^{I P N}\right)+\Pi\left(p_{1 H}^{I P N}\right)>2 \Pi\left(p_{1}^{E R}\right)$. We rewrite the difference using (11) as

$$
\begin{aligned}
& \Pi\left(p_{1 F}^{I P N}\right)+\Pi\left(p_{1 H}^{I P N}\right)-2 \Pi\left(p_{1}^{E R}\right)=\frac{1}{2}\left(p_{1 F}^{I P N}+p_{1 H}^{I P N}-2 p_{1}^{E R}\right) \\
& =\frac{1}{2}\left(p_{1 H}^{I P N}-p_{1 F}^{I P N}\right)-\frac{1}{2}\left(\Pi_{H}^{S Q}-\Pi_{F}^{S Q}\right) .
\end{aligned}
$$

We show that it is positive when evaluated at $C_{H}=C_{F}$ and that it is increasing in $C_{H}$.

When $C_{H}=C_{F}, \Pi_{H}^{S Q}=\Pi_{F}^{S Q}$ and $\Pi\left(p_{1 F}^{I P N}\right)+\Pi\left(p_{1 H}^{I P N}\right)-2 \Pi\left(p_{1}^{E R}\right)=\frac{1}{2}\left(p_{1 H}^{I P N}-p_{1 F}^{I P N}\right)$, which is positive by Assumption 3. This difference is increasing in $C_{H}$ :

$$
\frac{\partial\left(\Pi\left(p_{1 F}^{I P N}\right)+\Pi\left(p_{1 H}^{I P N}\right)-2 \Pi\left(p_{1}^{E R}\right)\right)}{\partial C_{H}}=\frac{1}{2}\left(\frac{\partial p_{1 H}^{I P N}}{\partial C_{H}}-\frac{\partial \Pi_{H}^{S Q}}{\partial C_{H}}\right)=\frac{t+C_{H}-p_{2 H}}{8 t},
$$


which is positive by part (iii) of Assumption 2.

\section{Proof of Proposition 9}

The proof of Proposition 9 is available upon request from the authors. 


\section{TABLES}

\begin{tabular}{|l|c|l|}
\hline $\begin{array}{l}\text { (Patients' price, firm's } \\
\text { price) }\end{array}$ & ER with weak threats & ER with tough threats \\
\hline $\begin{array}{l}\text { Negotiations in F succeed and } \\
\text { the firm accepts ER }\end{array}$ & \multicolumn{1}{|c|}{$\left(C_{F}, P_{F}\right)$ in F and $\left(C_{H}, P_{F}\right)$ in $\mathrm{H}$} \\
\hline $\begin{array}{l}\text { Negotiations in F succeed but } \\
\text { the firm rejects ER }\end{array}$ & $\left(C_{F}, P_{F}\right)$ in F and $\left(P_{H}, P_{H}\right)$ in $\mathrm{H}$ & $\left(C_{F}, P_{F}\right)$ in F and no sales in $\mathrm{H}$ \\
\hline Negotiations in F fail & $\begin{array}{l}\text { ER not proposed, product } \\
\text { delisted in both countries: } \\
\left(P_{F}, P_{F}\right) \text { in F and }\left(P_{H}, P_{H}\right) \text { in } \mathrm{H}\end{array}$ & No sales in either country \\
\hline
\end{tabular}

Table I: The types of ER by agency $\mathrm{H}$. 


\section{LEGENDS}

Table I: The types of ER by agency H.

Figure 1. Comparing independent price negotiations $\left(P_{i}^{*}\right)$ to weak-threats ER $\left(P^{E R}\right)$ as country H's size $(K)$ increases relative to country F's. The value of $R$ is derived in the Appendix (proof of Proposition 4). It decreases as $C_{F}$ increases. 


\section{FIGURE 1}

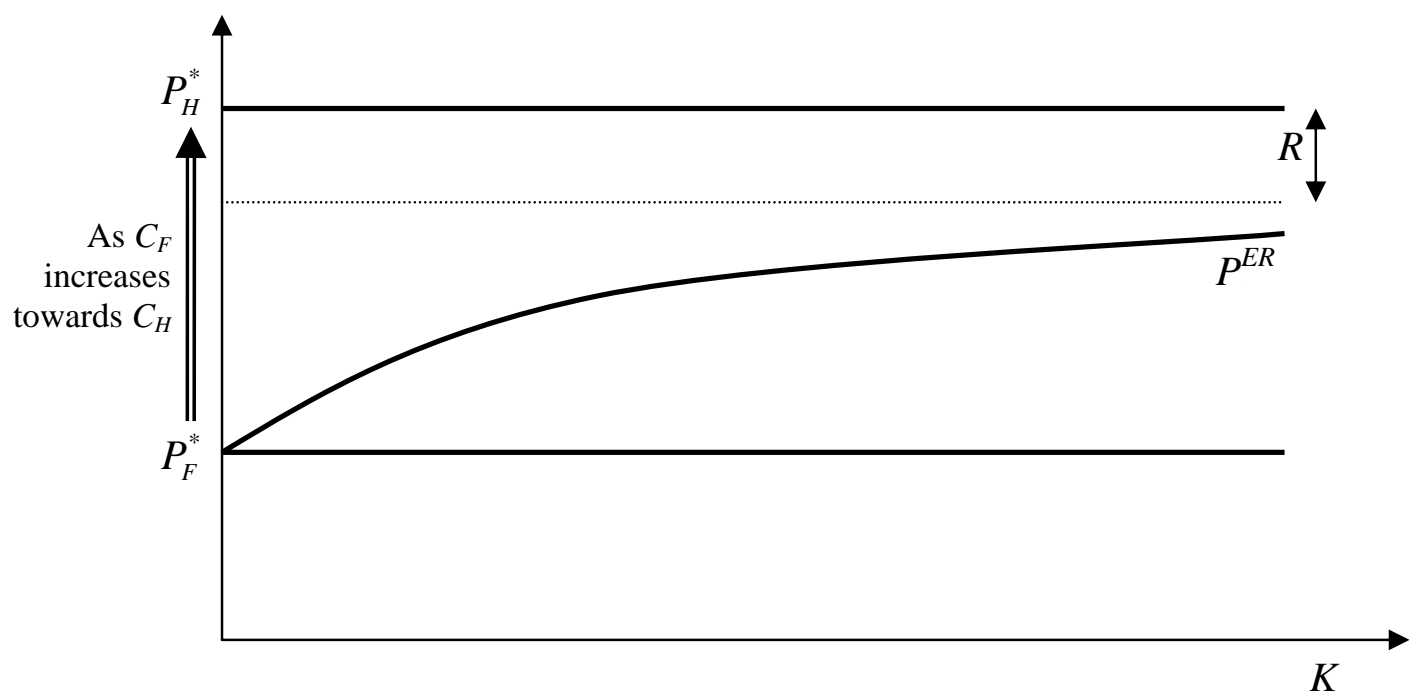

Figure 1. Comparing independent price negotiations $\left(P_{i}^{*}\right)$ to weak-threats ER $\left(P^{E R}\right)$ as country H's size $(K)$ increases relative to country F's. The value of $R$ is derived in the Appendix (proof of Proposition 4). It decreases as $C_{F}$ increases. 